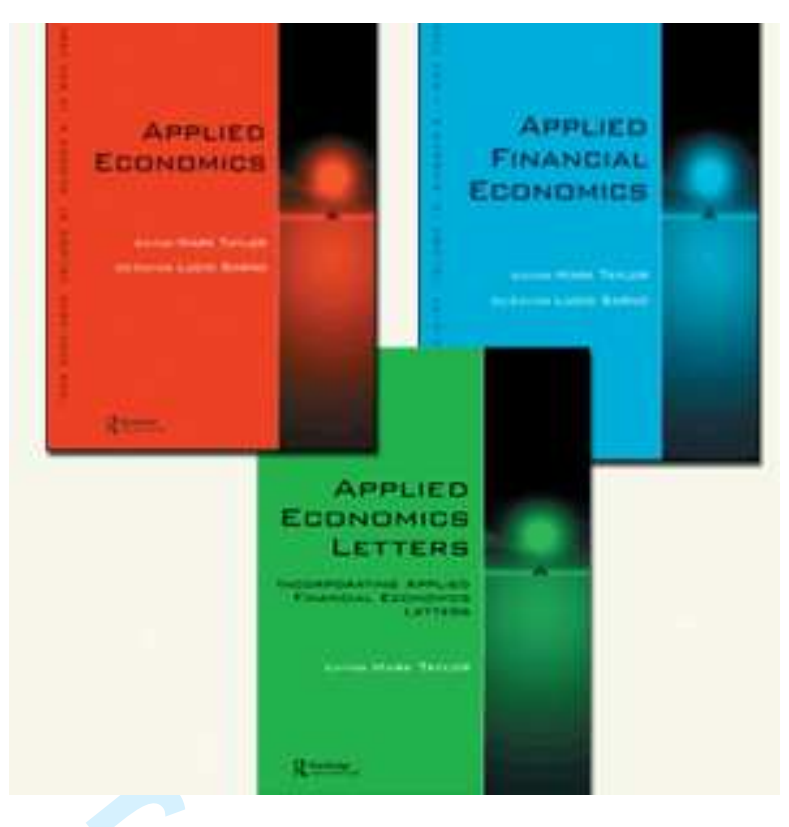

\title{
Contract Farmer and Poultry Farm Efficiency in Bangladesh: A Data Envelopment Analysis
}

\begin{tabular}{|c|c|}
\hline Journal: & Applied Economics \\
\hline Manuscript ID: & APE-2009-0581.R1 \\
\hline Journal Selection: & Applied Economics \\
\hline $\begin{array}{r}\text { Date Submitted by the } \\
\text { Author: }\end{array}$ & 04-Jul-2010 \\
\hline Complete List of Authors: & $\begin{array}{l}\text { Begum, Ismat; Ghent University, Agricultural Economics; } \\
\text { Bangladesh Agricultural University, Agricultural Economics } \\
\text { Alam, Mohammad; Bangladesh Agricultural University, Agribusiness } \\
\text { and Marketing; Ghent University, Agricultural Economics } \\
\text { Buysse, Jeroen; Ghent University, Agricultural Economics } \\
\text { Frija, Aymen; Ghent University, Agricultural Economics } \\
\text { Huylenbroeck, Guido; Ghent University, Agricultural Economics }\end{array}$ \\
\hline JEL Code: & $\begin{array}{l}\text { C31 - Cross-Sectional Models|Spatial Models < C3 - Econometric } \\
\text { Methods: Multiple/Simultaneous Equation Models < C - } \\
\text { Mathematical and Quantitative Methods, N55 - Asia including Middle } \\
\text { East < N5 - Agriculture, Natural Resources, Environment, and } \\
\text { Extractive Industries < N - Economic History, O13 - Agriculture; } \\
\text { Natural Resources; Energy; Environment; Primary Products < O1 - } \\
\text { Economic Development < O - Economic Development, } \\
\text { Technological Change, and Growth, Q12 - Micro Analysis of Farm } \\
\text { Firms, Farm Households, and Farm Input Markets < Q1 - } \\
\text { Agriculture < Q - Agricultural and Natural Resource Economics }\end{array}$ \\
\hline
\end{tabular}


1

2

3

4

5

6

7

8

10

11

12

13

14

15

16

17

18

19

20

21

22

23

24

25

26

27

28

29

30

31

32

33

34

35

36

37

38

39

40

41

42

43

44

45

46

47

48

49

50

51

52

53

54

55

56

57

58

59

60 Keywords: $\begin{aligned} & \text { poultry contract farming, efficiency, DEA, Tobit analysis, } \\ & \text { Bangladesh }\end{aligned}$

ScholarONE" 
1

2 The economic growth and stability of Bangladesh is primarily dependent on agriculture. The

3 poultry sub-sector in comparison to other sectors has a high potential for growth for a wide range

4 of reasons. Poultry meat farming has a considerable potential for providing income opportunities,

5 reducing malnutrition, generating employment and alleviating poverty in Bangladesh (Jensen,

6 1999). Poultry meat has a great demand as compared to other meat, simply because of its low

7 cost as well as the religious taboos in case of pork and beef in Bangladesh.

8 In Bangladesh, commercial poultry farming started not earlier than the 1980's. Being a meat

9 deficit country with a fast growing population in an already densely populated country, from the

10 1990's Bangladesh has pursued a development policy in the poultry sector based on

11 enhancement of the commercial poultry meat production. This resulted in a spectacular increase

12 in the number of poultry farms (ECNEC, 1999). This policy has also led to a substantial increase

13 in poultry meat production from 66,357 thousand metric tons in 1990 to 102,000 thousand metric

14 tons in 2007 (FAOStat, 2008). However, the per capita yearly demand is $7.67 \mathrm{~kg} / \mathrm{year}$, whereas

15 per capita production is only $3 \mathrm{~kg} / \mathrm{year}$, resulting in a per capita deficit $4.67 \mathrm{~kg} / \mathrm{year}$. Thus the

16 current production is not so impressive given a deficiency of $61 \%$ meat demand in the country.

17 Under above circumstances, the poultry sector productivity growth needs to be fostered, either 18 through technological development or an increase in production efficiency or a combination of 19 both, in order to stand the demand pressure and self sufficiency of meat production. Therefore, it 20 appears that commercial poultry farming systems must be further developed and ways must be 21 sought to improve the efficiency of the existing production technology. To this end, measuring 22 farms' efficiency is an important issue that could be a first logical step in a process that leads to 23 substantial resources utilization improvement. 
24 The present farming system of poultry meat in Bangladesh can be broadly divided into two 25 systems: the traditional rural backyard and the commercial farming. The commercial farming 26 system can be also divided into two types, the independent farming and the contract farming 27 system. In the case of independent farming, farmers run their business by themselves without any 28 contractual agreement with a third party, bear all production expenses by themselves and accept 29 all the risks and benefits resulting from their decisions. On the other hand, the contract farmers 30 have a contractual agreement with the integrator for supply or purchase of inputs and for supply 31 or sale of outputs at pre-determined prices. The integrator also provides technical know-how to 32 the contract farmers through a company supervisor.

33 Contract farming has been introduced in poultry farming in Bangladesh in 1994 by a big 34 agribusiness company, named ABFL (AFTAB Bahumukhi (multipurpose) Farm Limited). 35 Contract farming could be a possible way to increase farm's efficiency but none of the previous 36 studies have provided an in-depth explanation about the role of vertically integrated poultry 37 contract farming systems on farm efficiency.

38 In an economy where technologies are lacking, efficiency studies show the possibility of raising 39 productivity by improving efficiency without increasing the resource base or developing new 40 technology (Yusuf and Malomo, 2007). It also helps to determine the under utilization or over 41 utilization of input factors. Therefore, the aim of this paper is to investigate technical, allocative 42 and economic efficiency of poultry farms in Bangladesh. Many researchers have used DEA as a 43 useful tool to investigate efficiency in the agricultural sector (Kelvin Balcombe et al., 2008; 44 Zaibet \& Dharmapala, 1999) but a less research studies (Lansink. A. O. and Reinhard. S., 2004) 45 using focus on the efficiency of livestock farm. We used data envelopment analysis (DEA) in 46 order to estimate consistent measures of efficiency. Next, the paper assesses the determinants of 
47 efficiency measures using a Tobit or censored regression model and also to estimate elasticities

48 to provide the information on the magnitude of the variables influence on technical, allocative 49 and economic efficiency. Although there have been several studies that have analyzed the 50 efficiency of agricultural production in Bangladesh (Kamruzzaman et al., 2007; Wadud and 51 White, 2000; Coelli et al., 2002), but most of them have focused on major food crops like rice, 52 wheat, etc. To our knowledge, so far no studies have focused on poultry meat farms in 53 Bangladesh, which makes this paper unique for the Bangladesh context. This study gives 54 valuable information for policy makers, not only because it generates awareness concerning 55 inefficiencies in poultry farms, but also provides insight into possible improvements by 56 exploring the determinants of these inefficiencies.

57 The remainder of the paper is organized as follows. The next section II presents the methodology 58 of the study. The DEA models used for our efficiency calculations in addition to the sample size 59 and data collection are described in this section. Results concerning various efficiency scores, 60 their determinants and efficiency elasticities are presented and discussed in Section III. Section $61 \quad$ IV provides conclusions.

\section{II. Methodology}

\section{Model specification}

64 Efficiency is a widely used concept in economics. Economic efficiency could be expressed as a 65 combination of technical and allocative efficiencies. Technical efficiency gives an idea about 66 how to minimize input utilization in the production process of a given output vector. 67 Alternatively, it also refers to how to maximize an output vector without changing input 68 quantities used. In this sense, a given farm is technically efficient only if it is impossible to 69 increase the quantity of output without increasing the use of one, or many, inputs or if, for a 
70 given level of output, it is impossible to decrease the level of inputs used. Allocative efficiency

71 measures the ability of the farmer to use inputs in optimal proportions given input prices.

72 Economic efficiency (EE) finally is the product of allocative and technical efficiency and

73 captures performance in both measures. Different methods were used by several researchers to

74 measure the allocative and technical efficiency in different sectors of economy. Among them

75 there are two widely used efficiency measurement methods of a decision making unit, one is the

76 non-parametric Data Envelopment Analysis (DEA) and the other is the parametric Stochastic

77 Frontier Analysis (SFA). Some studies have compared the two approaches (DEA \& SFA)

78 (Lovell (1993); Sharma et al. (1997); Hjalmarsson et al. (1996); Fecher et al. (1993)).The choice

79 between the stochastic frontier approach and DEA approach to measure efficiency will therefore

80 depend mainly on the objective of the research, the type of firms and the data availability.

81 The framework for the non-parametric DEA method was initiated by Farrell (1957) and

82 reformulated as a mathematical programming problem by Charnes, Cooper and Rhodes (1978).

83 Given a number of producing units, which are called "Decision Making Units" (DMUs), the

84 DEA model constructs an efficiency frontier from the sample of the best performing DMUs.

85 Units that are not on the frontier are considered to be inefficient. The method enables to find out

86 the relative efficiency of a given farm by examining its position in relation to the optimal

87 situation. The strength of DEA is that it does not require any assumptions about the functional

88 form of the production technology.

89 DEA at constant return to scale (CRS) means that for a DMU producing an output $\mathrm{Y}$ by using an 90 input $X$, it is feasible to produce $a Y$ using $a X$ amount of input ( $a$ is a scalar). The assumption of

91 constant returns to scale is not true where increased amounts of inputs used do not proportionally

92 increase the amount of output produced (Speelman et al., 2008). For this reason, a variable 
93 returns to scale (VRS) assumption is also considered in the efficiency calculation. In fact, to 94 know whether production is either CRS or VRS, the values of efficiency levels are calculated 95 using the DEA technique under both assumptions and then compared. The comparison of 96 efficiency levels of CRS and VRS assumptions gives also information on the scale efficiency.

97 The scale efficiency is higher if the VRS efficiency estimates converge to the CRS efficiency 98 estimate.

99 DEA can be input or output-oriented where the difference is that either the objective is to 100 continue using the same amount of inputs while producing more outputs (output-oriented DEA) 101 or the objective is to produce the same amount of output by using fewer inputs (input-oriented 102 DEA) (Speelman et al., 2008). This study uses an input-oriented approach that reflects the 103 objective of a decrease in scarce resources (input) use.

104 DEA uses data of the individual poultry farmers that are called DMUs in the DEA context. The $\mathrm{k}$ $105=1, \ldots, \mathrm{K}$ DMUs produce $\mathrm{m}=1, \ldots \mathrm{M}$ outputs using $\mathrm{k}=1, \ldots \mathrm{N}$ inputs. Each farmer (the 106 DMU) can decide individually upon both inputs and outputs. The $\mathrm{K} \times \mathrm{N}$ input matrix $\mathbf{X}$ and the $107 \mathrm{M} \times \mathrm{N}$ output matrix $\mathbf{Y}$ represent the data for all the farms.

108 The most common approach to asses CRS efficiencies is the use of following programming 109 model as proposed by Charnes et al. (1978):

$110 \operatorname{Min}_{\theta, \lambda} \theta$

111 Subject to $-y_{i}+\mathbf{Y} \lambda \geq 0$

$112 \theta \mathrm{x}_{\mathrm{i}}-\mathbf{X} \boldsymbol{\lambda} \geq 0$

$113 \lambda \geq 0$. 
114 Where $\theta$ is a scalar and $\lambda$ is a vector of constants, $x i$ and $y i$, are column vectors with the input and 115 output data for the $\mathrm{i}$-th farm. The value $\theta$ is a score always lying between zero and one, with a 116 value of one indicating that the farm lies on the frontier and is efficient. The implicit assumption 117 of the model described above of constant returns to scale can be relaxed by adding a convexity 118 constraint: $\mathrm{I1}^{\prime} \lambda=1$, with I1 a vector of one's (Banker et al., 1984).

119 However, based on the technical and allocative efficiency the economic efficiency can be 120 determined as $\mathrm{EE}^{1}=\mathrm{AE}^{*} \mathrm{TE}$. Allocative efficiency itself is calculated in two steps. First a cost121 minimizing vector of input quantities given the input prices is determined using the model from 122 program 2:

$123 \operatorname{Min}_{\mathrm{xi} *, \lambda} \mathrm{w}^{\prime} \mathrm{x}_{\mathrm{i}}^{*}$

124 Subject to $-y_{i}+Y \lambda \geq 0$

$125 \mathrm{x}_{\mathrm{i}}{ }^{*}-\mathrm{X} \lambda \geq 0$

$126 \mathrm{I}^{\prime} \lambda=1$

$127 \lambda \geq 0$.

128 where, $\mathrm{w}$ is a vector of input prices for the $\mathrm{i}$-th farm and $x_{i}$ (which is calculated by using linear 129 programming) is the cost-minimizing vector of input quantities for the $\mathrm{i}$-th farm, given the input 130 prices $\mathbf{w}$ and the output levels $y_{i}$. The other symbols are defined the same as in equation 1 . The 131 economic efficiency (EE) of $\mathrm{i}$-th farm is calculated as the ratio of the minimum cost to the 132 observed cost (equation 2)

$133 E E=w_{i} x_{i} * / w_{i} x_{i}$

134 Data and field survey

${ }^{1}$ Called also "cost efficiency" (Coelli, 1996) 
135 The analysis was based on primary data collected through a comprehensive field survey. A 136 sample of 75 farms was chosen. The data were composed by Excel and finally analyzed by a 137 DEA-Solver, namely Win4DEAP (Coelli, T. J., 1996). We used also the STATA software to 138 resolve the Tobit regression and elasticities.

139 Kaliakoir and Sripur Thanas under the Gazipur district (see Figure 1) were selected as 140 representative study areas for commercial poultry farm because the district has been declared by 141 the government of Bangladesh as poultry region and have a high concentration of poultry farms. 142 The other study area was Kishorganj district where the pioneer integrated company ABFL 143 offering contracts is situated. The two regions were necessary to include in the analysis to 144 compare both contract (Kishorganj) and non-contract farmers (Kaliakoir and Sripur Thanas). 145 Both regions have well road communication and transportation facilities with the country's 146 capital city Dhaka, which is the main poultry output and input market for the both areas. 147 Therefore we assume that there can be no systematic region effect in the analysis.

148 Contract farming data were collected from two Upazilla (an administrative area), Bajitpur and 149 Kuliarchar under Kishorganj district. The summaries of the main features of the contract 150 arrangements of ABFL are highlighted in Table 1. According to the agreement ABFL provides 151 day old chicks, feed, veterinary supplies, which have been given on credit, and implement final 152 marketing of the output. The company also provides technical assistance for the poultry 153 producer. From other side, the farmer provides space, equipment, labor, and daily management. 154 ABFL buys back the matured birds at a pre-determined price and the credit is then adjusted to 155 the price of the farmer's product. One requirement that farmers must meet in order to participate 156 in contract farming is providing land and housing for chicks. However, farmers can decide the 157 number of chicks they wish to raise. 
158 A field survey was carried out on 75 commercial poultry farms (25 independent and 50 contract 159 poultry farms) randomly. In the case of contract farming, stratified sample has been used to 160 obtain and proportional distribution of farm size. The entire study population of all 560 contract 161 growing farmers, obtained from ABFL officials, was categorized to their farm sizes as follows: 162 1) small farmers raising 1200 birds, 2) medium farmers raising 1201 up to 2000 birds, 3) large 163 farmers raising more than 2000 birds. This subdivision has lead to 202 small, 280 medium, and 16478 large farms. The selected sample of 50 contract farms contains therefore 18 small, 25 medium 165 and 7 large farms.

166 Avian influenza's outbreak H5N1 affected poultry farming in eight Asian countries (Cambodia, 167 China, Indonesia, Japan, Laos, South Korea, Thailand, and Vietnam) during late 2003 and early 168 2004. Although at that time there was no bird flu in Bangladesh, but the suspicion of bird flu 169 poultry sector and the resulting consumer reactions has lead to great financial losses. The death 170 of some people at that time by unknown diseases in different places of Bangladesh made the 171 suspicion stronger. People had initially wrongly attributed this to avian influenza. Only a few 172 months later the news came that the suspicious deaths were due to the virus of NIPAH. 173 Nevertheless, since 2003, the Bangladesh poultry industry is every year affected by either bird 174 flu rumours or bird flu itself. Therefore, the analysis relies on data of the year 2002 to compare 175 efficiency of the two systems.

176 The period of investigation of this study covered the whole year of 2002. Data were collected in 177 January to March, 2003. Figure 1 indicates the map of study area.

$178<$ Introduce Figure 1 about here>

179 < Introduce Table 1 about here> 


\section{III. Results and interpretations}

\section{Efficiency measurement}

182 The costs of the sampled poultry farm include labor, day old chicks, feed, vaccine and medicine, 183 transportation, litter, equipment and housing cost. For the measurement of economic efficiency 184 only the following inputs were used because they are the most important and they are available 185 in both physical and monetary terms: (i) human labor (man-days) and wage rate; (ii) day old 186 chicks (cumulative weight) and price of that, and (iii) feed (kilogram) and price of per kilogram 187 feed. The sum of these inputs covers 75 to 80 per cent of the total cost (Begum 2005; Bhuiyan, 188 2003). Table 2 reports the results of test of equal means between independent and contract 189 farming for the variables used in the estimation and also show the maximum and minimum value 190 of sample variables. The same table highlights several clear differences in output and input uses 191 between the two farming system. Day old chick data were recorded by the cumulative weight 192 (cwt.) of one day old birds. Output data were also recorded by the cumulative weight of sold 193 birds. The average input-output prices data which are collected from field survey and used in 194 data envelopment analysis are also presented in Table 2. Table shows that the labor and feed 195 prices are the same in both farming systems while day old chick prices vary between the 196 systems. This variation depends largely on breed quality. Independent farmers purchased 197 different types of strains of day old chicks from the nearby hatchery of the study area, such as 198 Phoenix, Paragon, Kazi. Most of the farmers chose the strain of 'Hubbard', because it's lower 199 mortality and higher disease resistance. Farmers also choose Vancobb, Starbro, Casila, Hi-sex, 200 Ross, because of the good performance on growth and body weight. Contract farmers are bound 201 to choose one out of three strains: I-757, MPK and Arbor-Acres. The average day old chick 
202 prices of independent and contract farm were 24 and $15 T a k a^{2}$ respectively. The price of day old 203 chicks may vary between strains. In the case of contract farms, farmers have to contribute 1.50 204 Taka per chick to the fund at the time of purchase DOCs as insurance premium. ABFL is the 205 only farm in Bangladesh that introduced an internal insurance scheme to cover the risk of loss 206 and safeguard the interest of the contract growing farmers in case of immature death of chicks by 207 diseases and other cogent reasons. According to this scheme, ABFL operates a contributory 208 security fund. Depending on the chick mortality a portion of the initial contribution or risk 209 premium is refunded. For example, if the chick mortality is less than 3 per cent, 4-6 per cent, 721010 per cent and $11-15$ per cent then $80,40,20,10$ per cent of the contribution respectively is 211 refunded to the farmer. If the mortality rate is above 15 per cent, the farmer can claim full 212 insurance compensation. In this case, for birds up to 20 days age 20 Taka per bird is paid after 213 deducting 15 per cent from the total number of lost birds. For birds beyond 20 days old, 30 Taka 214 is paid per bird after calculating the benefits from birds up to 20 days old. This means lower 215 mortality rates leads to higher rates of compensation, but over $15 \%$ mortality leads to claim of 216 full insured value compensation. This insurance scheme contains thus incentives to carefully 217 manage the bird but also an insurance against force majeure.

218 <Introduce Table 2 About Here>

219 <Introduce Table 3 About Here>

220 The frequency distribution of the efficiency estimates obtained from the DEA frontier and their 221 summary statistics are presented in Table 3. Given the large variability in the computed 222 measures, efficiency scores are clustered into five groups such as $60-70 \%, 71-80 \%, 81-90 \%$, $22391-99 \%$ and $100 \%$. The estimated mean values of technical, allocative and economic efficiency

${ }^{2} 1 \mathrm{US} \$=58.50 \mathrm{Taka}, 2003$ 
224 are 86, 87 and 74 and 93, 99 and 93 per cent for independent and contract poultry farms in CRS 225 DEA frontier, respectively and those are 91, 89 and 81 and 96, 98 and 94 per cent for VRS DEA 226 frontier. The results of DEA analysis reveal significant differences between the efficiency level 227 of independent and contract poultry farms. Therefore, there is some scope for reducing cost in 228 production and hence obtaining output gains through efficiency improvement. In terms of scale 229 economics, 53 per cent farms are characterized by increasing return to scale, 12 per cent farms 230 have constant return to scale and 35 per cent farms are characterized by decreasing return to 231 scale (Table 4). If all farms are using the same technology, then we would expect returns to scale 232 to be increasing for farms with a relatively low output and decreasing return to scale farms with a 233 relatively high output. Constant return to scale would be expected for farms with an output level 234 equal to mean output (Silberberg, 1990). The mean output of the sub-optimal scale is larger than 235 the super-optimal as well as optimal scale for the sample poultry farms (Table 4). The results 236 indicate that the sub-optimal output levels overlap a great portion of the optimal and super 237 optimal output values.

$238<$ Introduce Table 4 About Here>

239 Identifying factors of efficiency using Tobit analysis

240 The second step in the analysis is to identify the factors that influence the farm technical, 241 allocative and scale efficiency by using a Tobit model and also to estimate elasticities to provide 242 the information on the magnitude of the variables influence on technical, allocative and 243 economic efficiency.

244 The factors used in this study consist mainly of farm's human capital variables. The set of 245 variables includes farmer's age, farmer's educational background or schooling (number of 
246 years), farmer's occupation indicating whether the poultry farming is considered as main or

247 subsidiary occupation, poultry farm size and participation in contractual system.

248 To explain efficiency scores variation across farms, many research studies regressed the 249 efficiency scores on the farm-level characteristics, using a Tobit model, since the efficiencies 250 vary from zero to unity (Reig-Martinez and Picazo-Tadeo, 2004; Iraizoz et al., 2003; Lockheed 251 et al., 1981). In this research, Tobit analysis has been used because the dependent variable, initial 252 efficiency $\left(\mathrm{IE}_{\mathrm{i}}\right)$ calculated by DEA model, is a censored variable with an upper limit of one. This 253 Tobit model is employed using DEA method to estimate the factors associated with efficiency 254 with the help of STATA software. The model could be written as following:

$$
\mathrm{IE}_{\mathrm{i}}=\alpha 0+\alpha 1 \mathrm{AG}+\alpha 2 \mathrm{sch}+\alpha 3 \mathrm{Ocu}+\alpha 5 \mathrm{Cont}+\varepsilon
$$

256 Where,

$257 \mathrm{IE}_{\mathrm{i}}$ is the technical, allocative or economic efficiency of poultry farms,

258 AG is the age of the farmers in years,

259 Sch is the schooling /education level of the farmers (years),

260 Ocu is the main occupation of the farmer dummy variables $=1$ if poultry farming, $=0$ otherwise, 261 Cont is the contracting on poultry framing dummy variable $=1$ if farmer engaged with contract 262 framing, $=0$ otherwise,

$263 \varepsilon$ is the error term.

264 Both the CRS and VRS specification scores were regressed. The results are presented in table 5. 265 The results show that the contract system is an important explaining dummy variable which is 266 positively and significantly related to farm's technical, allocative and economic efficiency (Table $2675)$. 
268 The Tobit results also show that the age of the farmer is positively and significantly related to

269 farm's allocative efficiency. This is expected because the higher aged farmers are more likely to

270 be efficient to allocate their scarce resource as compared to their less aged counterparts as a 271 result of their better skills and experience.

272 < Introduce Table 5 About Here>

273 The main occupation of the farmer is positively and significantly related to farm's allocative \& 274 economic efficiency in CRS. This positive effect for full time poultry farmers can be explained 275 by the fact that specialization increases efficiency.

276 Formal education, commonly measured in years of schooling, is the farmer attribute that seems 277 to have received more attention in the efficiency literature. In this study farmer's schooling is 278 insignificant to both CRS and VRS efficiencies in the models. Various other studies also have 279 found no statistically significant relationship between these two variables (Bravo-Ureta and 280 Evenson, 1994; Kalirajan, 1991; Phillips and Marble, 1986).

281 In this section we also estimate efficiency elasticities to provide information on the magnitude of 282 the variables which are used in the Tobit model. For doing so, we used STATA software and the 283 derivation strategy was followed from Rahman and Rahman (2008) although the estimation 284 process of efficiency elasticities originally adopts the framework of Frame and Coelli (2001). 285 However, to calculate elasticity we first need to estimates the marginal effects of efficiency 286 (technical, allocative and economic efficiency scores regressed in the Tobit models) of the $i_{\text {th }}$ 287 farm with respect to $j_{\text {th }} Z$ vector. To calculate elasticity of the $i_{\text {th }}$ farm with respect to $j_{\text {th }} Z$ vector 288 we apply the following equation

$\eta E_{i j}=\frac{d E_{i j}}{d Z_{i j}} \cdot \frac{Z_{i j}}{E_{i}}$ 
290 Where $d E_{i j} / d Z_{i j}$ is the marginal effect of the variable $Z_{i j}$ on the efficiency $E_{i j}$ derived from tobit 291 regression.

292 Our elasticity estimate reveals that efficiency will increase if the farmer's main occupation is 293 poultry farming (Table 6). In fact, a $1 \%$ increases in the number of contract farms increases 294 technical, allocative and economic efficiency by $0.05 \%, 0.09 \%$ and $0.14 \%$, respectively in CRS 295 specification and $0.03 \%, 0.07 \%$ and $0.09 \%$, respectively in VRS specification (Table 6). This is 296 expected because under contractual agreement, in order to obtain sufficient supplies of the right 297 quality of poultry meat and at the right time, the company provides technical know-how 298 assistance through company's recruited supervisor, production inputs \& services, and production 299 credit along with intensive supervision (Figure 2), which in turn improves farm efficiency. By 300 receiving technical knowledge from company's supervisor contract farmers have gained more 301 knowledge on their resource and practices, which enables them to use resources more efficiently. 302 For instance, commercial poultry farming requires highly technical knowledge to produce 303 chicken efficiently which is not always easy to adopt for illiterate or little educated farmers. The 304 highly technical knowledge refers to knowledge of keeping temperatures for rearing poultry 305 birds appropriately, the appropriate timing of feeding, lighting and vaccination. A broiler needs 306 different temperatures in different stages of its growth. For example, it needs $35^{0} \mathrm{C}, 32.2^{0} \mathrm{C}$, $30729.4^{0} \mathrm{C}, 26.6^{0} \mathrm{C}$ and $23.7^{0} \mathrm{C}$ in the $1^{\text {st }}, 2^{\text {nd }}, 3^{\text {rd }}, 4^{\text {th }}$ and $5^{\text {th }}$ week, respectively. Furthermore 308 appropriate lighting according to the age of the day-old chicks is also important for its growth. 309 Also, the feed amount of day-old chicks varies according to growing stage. A day-old chick 310 requires everyday $10 \mathrm{~g}, 20 \mathrm{~g}, 30 \mathrm{~g}$, and $40 \mathrm{~g}$ of feed, in the $1^{\text {st }}, 2^{\text {nd }}, 3^{\text {rd }}$ and $4^{\text {th }}$ week, respectively. 311 Finally, a broiler requires $100 \mathrm{~g}$ of feed everyday in $10^{\text {th }}$ week. Timely vaccination of birds is 312 also important for the growth of chicks. Thus the information transfer may involve knowledge 
313 about feed mixtures or feed timing, lighting and heating knowledge that result in higher 314 efficiency. Besides, it is possible that the inputs and services provided by the integrator/ 315 company, such as feed, veterinary care, and especially the breed quality of day old chick, may be 316 superior to that available to an independent farmer, resulting in efficiency gain. Consequently, 317 part of the estimated gains in efficiency may be the result of our inability to account for quality 318 differences in the inputs. Some of the efficiency gains from contracting might be explained by 319 differences in access to capital - if contract farmers are able to obtain more financing support 320 because they face less risk then they could more easily adopt newer and more productive capital 321 equipment (such as brooder, generator), than independent farmers. For the same financial 322 resources as independent farmers, contract growers could obtain technology (as contract farmers 323 do not have to purchase DOCs, feed, and medicine provided by integrators) that is more 324 productive and thus achieve more efficient scale of production.

$325<$ Introduce Table 6 About Here>

326 <Introduce Figure 2 About Here>

327 IV. Conclusion

328 In this study technical, allocative and economic inefficiency in the poultry farms of Bangladesh 329 has been estimated by using the DEA approach and the variation in economic inefficiency is 330 explained using various farm-specific human capital variables. The results have shown that 331 under constant return to scale (CRS) and variable returns to scale (VRS) specification, technical, 332 allocative and economic efficiencies are on average 91\%, 94\%, 85\% and 94\%, 95\%, 89\% 333 respectively. But under CRS and VRS specification, technical, allocative and economic 334 efficiencies of the independent farms are $86 \%, 87 \%, 74 \% ; 91 \%, 89 \%$, and $81 \%$, respectively 335 which are below than the contract farm $(93 \%, 99 \%, 93 \% ; 96 \%, 98 \%$, and 94\%, respectively). 
336 The farm households appear to be dominantly operating at increasing returns to scale. The 337 sample farmers, on average, could increase their poultry production if they could operate at full 338 technical, allocative and economic efficiency levels, given the existing technology. The results of 339 Tobit regression show that contract farms are more efficient than independent farms. Evaluating 340 factors associated with inefficiency suggests that engagement in contract farming is the most 341 statistically significant factor associated with technical, allocative and economic inefficiency. 342 The elasticity estimate reveals that a $1 \%$ increase in the number of contract farm increases 343 technical, allocative and economic efficiency by $0.05 \%, 0.09 \%$ and $0.14 \%$, respectively in CRS 344 specification and $0.03 \%, 0.07 \%$ and $0.09 \%$, respectively in the VRS specification. This increased 345 efficiency of contract farming may be due to a transfer of technical "know how" from integrators 346 to farmers. Inefficient farms have used an excess amount of inputs on poultry farms in a rural 347 area of Bangladesh. Thus the results of the study give information to policy makers and 348 extension services on how to better aim efforts to improve poultry farm efficiency.

349 Contract farming could be a good way to promote efficiency at farm level. It is, however, not 350 immediately possible to set up a nationwide integrated contract farm in the short run because the 351 establishment of such integrated contract farm requires huge support from the banking system 352 for credit and from various players for ensuring quality inputs such as feeds, day-old chicks and 353 vaccines. On the other hand the government has to monitor whether or not integrated farms is 354 dominating the market and mis-using market power. It can be suggested that to increase poultry 355 production and develop the poultry industry, the government as well as other private integrators 356 can take initiatives to spread an effective and well organized vertically integrated contract 357 farming system in Bangladesh. 
358

359

360

361

362

363

364

365

366

367

368

369

370

371

372

373

374

375

376

377

378

379

\section{References}

Banker, R. D., Charnes, A., Cooper, W.W. (1984) Some models for estimating technical and scale inefficiencies in Data Envelopment Analysis. Management Science, 30 (9), pp. 10781092.

Begum, I. A. (2005) An assessment of vertically integrated contract poultry farming: A case study in Bangladesh. International Journal of Poultry Science, 4 (3), pp. 167-176.

Bhuiyan, H. A. (2003) A comparative economic analysis of poultry production under supervision of Aftab Bahumukhi farm and own management in some selected areas of Kishorganj district. M.S. Thesis, Department of Agricultural Economics, Bangladesh Agricultural University, Bangladesh

Bravo-Ureta, B. E. and Evenson, R. E. (1994) Efficiency in agricultural production: The case of peasant farmers in Eastern Paraguay. Agricultural Economics, 10, pp. 23-37.

Charnes, A., Cooper,W. \& Rhodes, E. (1978) Measuring the efficiency of decision-making units. European Journal of Operational Research, 2, pp. 439-444.

Coelli, T. J. (1996) A Guide to DEAP Version 2.1: A Data Envelopment Analysis (Computer) Program, CEPA Working Paper No. 8/96, Department of Econometrics, University of New England

Coelli, T., Rahman, S. and Thirle, C. (2002) Technical, allocative, cost and scale efficiencies in Bangladesh rice cultivation: a non-parametric approach. Journal of Agricultural Economics, 53, pp. 607-626.

ECNEC. (1999) Executive Committee of National Economic Council (ECNEC) report, Planning Commission, Government of the Peoples of Republic of Bangladesh 
380 FAO. (2008) FAO Statistical database of Food and Agriculture Organization of the United $381 \quad$ Nations, Rome

382 Farrell, M. J. (1957) The measurement of productive efficiency. Journal of the Royal Statistics 383 Society. Series A (General), 3, pp. 120-134.

384 Fecher, F., Kessler, D., Perelman, S., and Pestieau, P. (1993) Productive performance of the 385 French insurance industry, Journal of Productivity Analysis. 4, pp. 77-93.

386 Frame, W.S., and Coelli, T.J. (2001) U.S. Financial services consolidation: the case of corporate 387 credit unions. Review of Industrial Organisation. 18, pp. 229-242.

388 Hjalmarsson, L., Kumbhakar, S.C., and Heshmati, A. (1996) DEA, DFA and SFA: A comparison. $389 \quad$ Journal of Productivity Analysis. 7(2/3), pp. 303-328.

390 Iraizoz, B., Rapun, M., and Zabaleta, I., 2003. Assessing the technical efficiency of horticultural 391 production in Navarra, Spain. Agricultural Systems. 78, 387-403.

392 Jensen, H. A. (1999) Paradigm and Visions: Network for Poultry Production and Health in 393 Developing Countries. In F. Dolberg and P.H. Petersen, eds. Poultry as a Tool in Poverty 394 Eradication and Promotion of Gender Equality, pp.31-38. Proceedings workshop, March 22395 26, 1999, Tune Landboskole, Denmark

396 Kalirajan, K. (1991) The Importance of Efficient Use in the Adoption of Technology: A Micro 397 Panel Data Analysis. Journal of Productivity Analysis 2, no. 2: 113-26.

398 Kamruzzaman, M., M. Manos, B. Begum, and M.A.A. (2007) Evaluation of economic efficiency 399 of wheat farms in a region of Bangladesh under the input orientation model. Journal of the 400 Asia Pacific Economy, 11(1), pp. 123-142. 
401 Kelvin, B., Iain. F., Laurel., Mizanur, R. and Laurence, S.(2008) An application of the DEA 402 double bootstrap to examine sources of efficiency in Bangladesh rice farming. Applied $403 \quad$ Economics, 40, pp. 1919-1925.

404 Lansink, A. O. and Reinhard, S. (2004) Investigating technical efficiency and potential 405 technological change in Dutch pig farming. Agricultural Systems, 79, pp. 353-367.

406 Lockheed, M.E., Jamison, D. and Lau, L.J. (1981) Farmer education and farm efficiency: a 407 survey. Economic Development and Cultural Change, 29, pp. 37-76.

408 Lovell, C. A. K. (1993) Production Frontiers and Productive Efficiency in (Eds) H. O. Fried, C. 409 A. K. Lovell and S. S. Schmidt, The Measurement of Productive Efficiency. Oxford $410 \quad$ University Press, New York.

411 Phillips, J. M., and Robert, P. M. (1986) Farmer education and efficiency: a frontier production 412 function approach, Economics of Education Review, 5, pp. 257-264.

413 Rahman, S., and Rahman, M. (2008) Impact of land fragmentation and resource ownership on 414 productivity and efficiency: The case of rice producers in Bangladesh. Land Use Policy. $415 \quad 26(1)$, pp. 95-103.

416 Reig-Martinez, E., and Picazo-Tadeo, A.J., (2004) Analyzing farming systems with Data 417 Envelopment Analysis: citrus farming in Spain. Agricultural Systems. 82, 17-30.

418 Sharma K. R., Leung P., Zaleski H. M. (1997) Productive Efficiency of the Swine Industry in 419 Hawaii: Stochastic Frontier vs. Data Envelopment Analysis. Journal of Productivity $420 \quad$ Analysis 8 (4), pp. 447-459

421 Silberberg, E. (1990) The Structure of Economics: A mathematical Analysis, Second Edition, $422 \quad$ McGraw-Hill. 
423 Speelman, S., D'Hase, M., Buysse, J. and D'Haese, L. (2008) A measure for the efficiency of $424 \quad$ water use and its determinants, a case study of small-scale irrigation schemes in North-West 425 Province, South Africa. Agricultural Systems, 98, pp. 31-39.

426 Wadud, A., and B.White. (2000) Farm household efficiency in Bangladesh: A comparison of 427 stochastic frontier and DEA. Applied Economics, 32 (13), pp. 1665-1673.

428 Yusuf, S. A. and Malomo,O.( 2007) Technical efficiency of poultry egg production in Ogun 429 State: A Data Envelopment Analysis (DEA) approach, International Journal of Poultry $430 \quad$ Science, $6(9)$, pp. 622-629.

431 Zaibet. L and Dharmapala, P.S. (1999) Efficiency of government-supported horticulture: the case 432 of Oman. Agricultural Systems, 62, pp. 159-168. 
Table 1. Summary of salient features of contract arrangements of ABFL in the poultry in Bangladesh

\section{Particulars}

1. Name of the company

AFTAB Bahumukhi Farms Ltd. (ABFL)

2. Type of the company

Private Limited Company

3. Form of contract arrangement

Formal input-output

handled

4. Backward linkage for contracted

Company provides day old chicks, feed and veterinary product

and medical services on credit to contract farmers

5. Size of the contract farmers (in 560 contract farmers 2003)

6. Geographical locations covered

Only KISHORGANJ district

7. Volume of input/product delivered

100 MT feed per month for broiler per month

8. Value of input/service delivered

$\$ 854701$ per month for broiler per month

9. Forward linkage for contracted

Own sales center for dressed broiler, dealer for feed product/services

10. Criteria for selecting contract and day old chicks (DOC) farmers

11. location of supply outlet

Dressed broiler: mainly Dhaka and Chittagong

DOC and feed: whole Bangladesh

12. Volume of products supplied per

Dressed broiler: 7 metric ton./day day

13. Approximate market share of the

$10 \%$ for chicks company

14. Provision for enforcement of Mostly informal and social contract

15. System of ensuring product Inspection, supervision, lab. test quality

Source: Field survey (2003). 
Table 2. Basic statistics for the survey variables used in the DEA model

\begin{tabular}{|c|c|c|c|c|c|c|c|c|}
\hline \multirow[b]{2}{*}{ Variables } & \multicolumn{2}{|c|}{ Sample Mean } & \multirow[b]{2}{*}{ t-statistics } & \multirow{2}{*}{ Prob. $>|\mathbf{t}|$} & \multicolumn{2}{|c|}{ Maximum } & \multicolumn{2}{|c|}{ Minimum } \\
\hline & $\begin{array}{c}\text { Contract } \\
\text { system }\end{array}$ & $\begin{array}{l}\text { Independent } \\
\text { system }\end{array}$ & & & $\begin{array}{l}\text { Contract } \\
\text { system }\end{array}$ & $\begin{array}{l}\text { Independent } \\
\text { system }\end{array}$ & $\begin{array}{c}\text { Contract } \\
\text { system }\end{array}$ & $\begin{array}{l}\text { Independent } \\
\text { system }\end{array}$ \\
\hline Day old chick (cwt. Kg) & 367.16 & 170.08 & 5.03 & 0.0000 & 764 & 732 & 86 & 45 \\
\hline Day old chick (Taka) & 139034.6 & 96754.56 & 2.29 & 0.0272 & 298650 & 371800 & 31200 & 27820 \\
\hline Feed (cwt. Kg) & 20004.3 & 14364 & 2.044 & 0.0484 & 43250 & 56400 & 4582 & 4000 \\
\hline Feed cost $($ Taka $)$ & 272058.9 & 195350 & 2.04 & 0.0484 & 529660 & 767040 & 62310 & 54400 \\
\hline Labor (man-day) & 504.82 & 318.32 & 2.33 & 0.0236 & 1397 & 1450 & 70 & 59 \\
\hline Labor $(T a k a)$ & 17134 & 14063.5 & 1.15 & 0.1275 & 34000 & 54700 & 3800 & 4130 \\
\hline Output (Kg) & 11783.54 & 6763.68 & 3.67 & 0.0003 & 25792 & 26654 & 2568 & 1965 \\
\hline Output (Taka) & 629507.8 & 404201 & 2.87 & 0.0066 & 1228197 & 1562252 & 140786 & 115316 \\
\hline Age & 41.46 & 32.56 & 1.66 & 0.0000 & 65 & 45 & 20 & 24 \\
\hline Education & 6.7 & 7.96 & -1.28 & 0.1025 & 14 & 16 & 1 & 1 \\
\hline \multicolumn{9}{|l|}{ Average input price } \\
\hline Day-old-chicks & 15.00 & 24.00 & - & - & & & & \\
\hline Labor (man-day) & 70.00 & 70.00 & - & - & & & & \\
\hline Feed $(\mathrm{kg})$ & 13.60 & 13.60 & - & - & & & & \\
\hline \multicolumn{9}{|l|}{ Average output price } \\
\hline Matured bird (price/kg) & 54.00 & 61.00 & - & - & & & & \\
\hline
\end{tabular}

Source: Field survey, 2003

Note: cwt. means cumulative weighted 
Table 3. Frequency distribution of efficiency estimates from the DEA model

\begin{tabular}{|c|c|c|c|c|c|c|c|c|c|}
\hline \multirow{4}{*}{ Efficiency index (\%) } & \multicolumn{9}{|c|}{ DEA Frontier } \\
\hline & \multicolumn{9}{|c|}{ Number of Farms } \\
\hline & \multicolumn{3}{|c|}{ Independent system } & \multicolumn{3}{|c|}{ Contract system } & \multicolumn{3}{|c|}{ t-statistics } \\
\hline & TE & $\mathrm{AE}$ & $\mathrm{EE}$ & TE & $\mathrm{AE}$ & $\mathrm{EE}$ & TE & $\mathrm{AE}$ & $\mathrm{EE}$ \\
\hline \multicolumn{10}{|l|}{$C R S$} \\
\hline $61-70$ & 0 & 0 & $3(12)$ & 0 & 0 & 0 & - & - & - \\
\hline $71-80$ & $4(16)$ & $2(8)$ & $22(88)$ & 0 & 0 & 0 & - & - & - \\
\hline $81-90$ & $18(72)$ & $18(72)$ & 0 & $16(32)$ & $1(2)$ & $18(36)$ & - & - & - \\
\hline $91-99$ & $1(4)$ & $5(20)$ & 0 & $30(60)$ & $48(96)$ & $31(62)$ & - & - & - \\
\hline 100 & $2(8)$ & 0 & 0 & $4(8)$ & $1(2)$ & $1(2)$ & - & - & - \\
\hline Mean & 0.86 & 0.87 & 0.74 & 0.93 & 0.99 & 0.93 & $6.40(0.000)$ & $13.10(0.000)$ & $21.58(0.000)$ \\
\hline Standard deviation & 0.06 & 0.04 & 0.03 & 0.03 & 0.02 & 0.03 & & & \\
\hline Maximum & 1 & 1 & 1 & 1 & 1 & 1 & & & \\
\hline Minimum & 0.72 & 0.76 & 0.66 & 0.88 & 0.87 & 0.87 & & & \\
\hline \multicolumn{10}{|l|}{ VRS } \\
\hline $61-70$ & 0 & 0 & $1(4)$ & 0 & 0 & 0 & & & \\
\hline $71-80$ & $2(8)$ & $4(16)$ & $13(52)$ & 0 & 0 & 0 & & & \\
\hline $81-90$ & $10(40)$ & $10(40)$ & $8(32)$ & $5(10)$ & $1(2)$ & $12(24)$ & & & \\
\hline $91-99$ & $8(32)$ & $9(36)$ & $1(4)$ & $37(74)$ & $45(90)$ & $34(68)$ & & & \\
\hline 100 & $5(20)$ & $2(8)$ & $2(8)$ & $8(16)$ & $4(8)$ & $4(8)$ & & & \\
\hline Mean & 0.91 & 0.89 & 0.81 & 0.96 & 0.98 & 0.94 & $2.85(0.007)$ & $7.29(0.000)$ & $7.83(0.000)$ \\
\hline Standard deviation & 0.07 & 0.06 & 0.08 & 0.03 & 0.02 & 0.04 & & & \\
\hline Maximum & 1 & 1 & 1 & 1 & 1 & 1 & & & \\
\hline Minimum & 0.75 & 0.77 & 0.70 & 0.90 & 0.87 & 0.87 & & & \\
\hline
\end{tabular}

Note: 1) Figures in the parentheses indicate percentage of farms

2) In the case of t-statistics figures in the parentheses indicate probability statistics 
Table 4. Optimal, sub-optimal and super-optimal outputs for the poultry farm (in cwt)

\begin{tabular}{lccc}
\hline Scale & Number of farms (\%) & Mean output & Output range \\
\hline Optimal & $09(12)$ & 10621.33 & $6991-14251$ \\
Sub-optimal & $40(53)$ & 6107.7 & $1965-12003$ \\
Super-optimal & $26(35)$ & 16091.12 & $9532-26654$
\end{tabular}

Note: Figures in the parentheses indicate percentage of farms 
Table 5. Tobit regression analysis of factors associated with inefficiency

\begin{tabular}{|c|c|c|c|c|c|c|}
\hline \multirow[t]{3}{*}{ Factors } & \multicolumn{6}{|c|}{ DEA frontiers } \\
\hline & \multicolumn{3}{|c|}{ Constant return to scale (CRS) } & \multicolumn{3}{|c|}{ Variable return to scale (VRS) } \\
\hline & $\mathrm{TE}$ & $\mathrm{AE}$ & $\mathrm{EE}$ & $\mathrm{TE}$ & $\mathrm{AE}$ & $\mathrm{EE}$ \\
\hline Constant & $0.829^{\text {**** }}$ & $0.8479^{* * *}$ & $0.6982^{\text {**** }}$ & $0.9064^{\text {**** }}$ & $0.8549^{\text {**** }}$ & $0.7681^{\text {**** }}$ \\
\hline Age & 0.0005 & -0.00001 & 0.0004 & 0.0001 & $0.0008^{*}$ & 0.0009 \\
\hline Schooling & 0.0082 & -0.0026 & 0.0046 & -0.0017 & -0.0106 & -0.0106 \\
\hline Occupation & 0.0172 & $0.0155^{* *}$ & $0.0296^{* * *}$ & 0.0108 & 0.0093 & 0.0185 \\
\hline Contracting & $0.0689^{* * *}$ & $0.1249^{* * *}$ & $0.1759^{* * *}$ & $0.0418^{* * *}$ & $0.0945^{* * *}$ & $0.1274^{* * *}$ \\
\hline$\delta$ & 0.0501 & 0.0312 & 0.0346 & 0.058 & 0.0361 & 0.0596 \\
\hline Log-Likelihood & 97.40 & 146.45 & 138.87 & 71.66 & 115.73 & 81.50 \\
\hline $\operatorname{LR}\left(\chi^{2}\right)$ & 31.45 & 115.31 & 148.62 & 9.34 & 76.42 & 58.57 \\
\hline $\mathrm{P}>\chi^{2}$ & 0.000 & 0.000 & 0.000 & 0.053 & 0.000 & 0.000 \\
\hline $\begin{array}{l}\text { No. of } \\
\text { observation }\end{array}$ & 75 & 75 & 75 & 75 & 75 & 75 \\
\hline
\end{tabular}

Note: ${ }^{* * *},{ }^{* *} \&{ }^{*}$ indicates $1 \%, 5 \%$ \& $10 \%$ level of significance 
Table 6. Efficiency elasticities

\begin{tabular}{l|c|c|c|c|c|c}
\hline \multirow{2}{*}{ Factors } & \multicolumn{3}{|c|}{ Constant return to scale (CRS) } & \multicolumn{3}{c}{ Variable return to scale (VRS) } \\
\cline { 2 - 7 } & TE & AE & EE & TE & AE & EE \\
\hline Age & 0.0225 & -0.0019 & 0.0199 & 0.006 & $0.0346^{*}$ & 0.0417 \\
Schooling & 0.0032 & -0.001 & 0.0019 & -0.0006 & -0.004 & -0.0104 \\
Occupation & 0.0126 & $0.011^{* *}$ & $0.0231^{* * *}$ & 0.0076 & 0.0065 & 0.0138 \\
Contracting & $0.0505^{* * *}$ & $0.0887^{* * *}$ & $0.1373^{* * *}$ & $0.0296^{* * *}$ & $0.0662^{* * *}$ & $0.0948^{* * *}$ \\
\hline
\end{tabular}

Note: ${ }^{* * *},{ }^{* *} \&{ }^{*}$ indicates $1 \%, 5 \% \& 10 \%$ level of significance 
Figure 1. Map of the study area

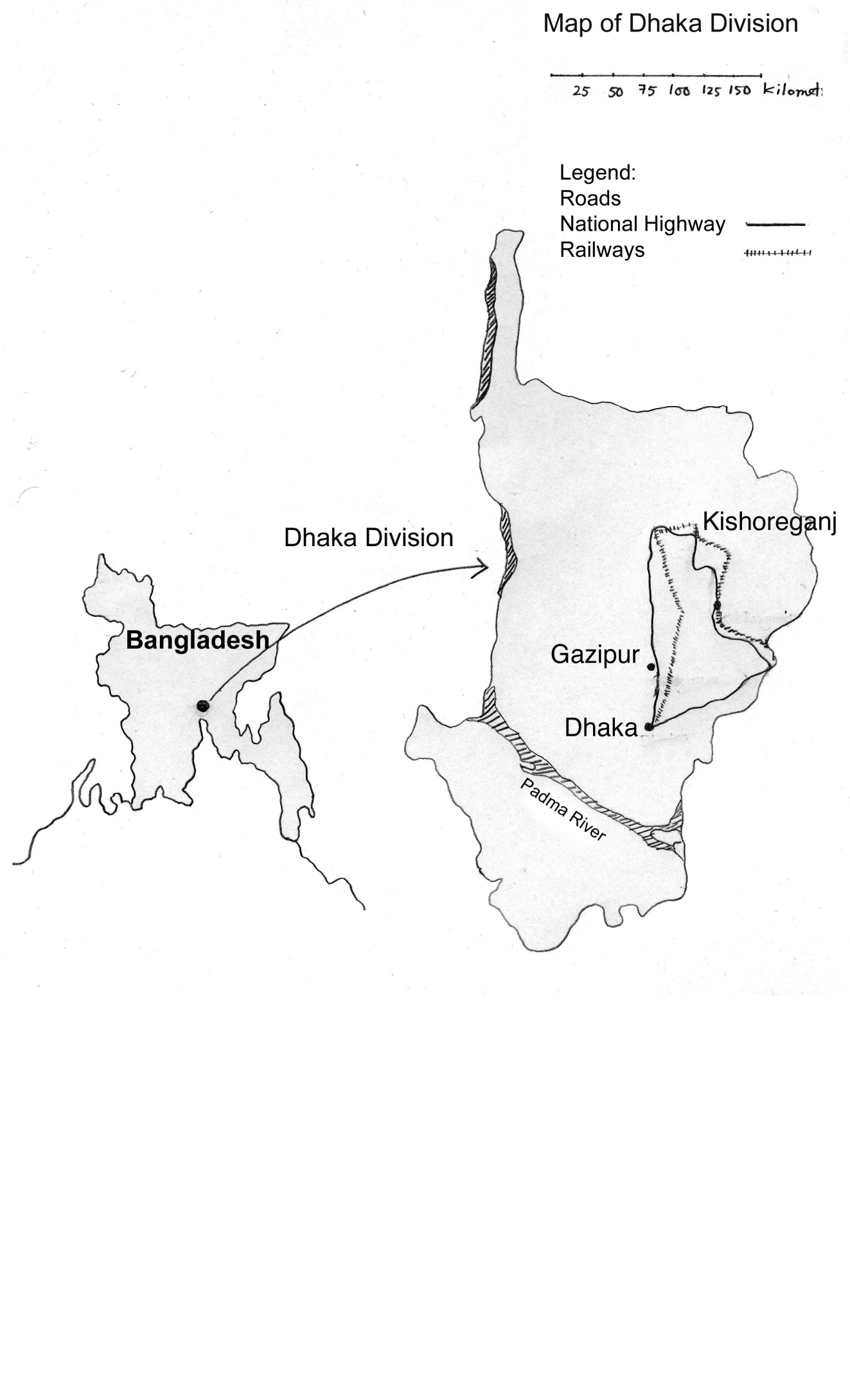


Figure 2. Vertical stages of poultry contract farming system in Bangladesh

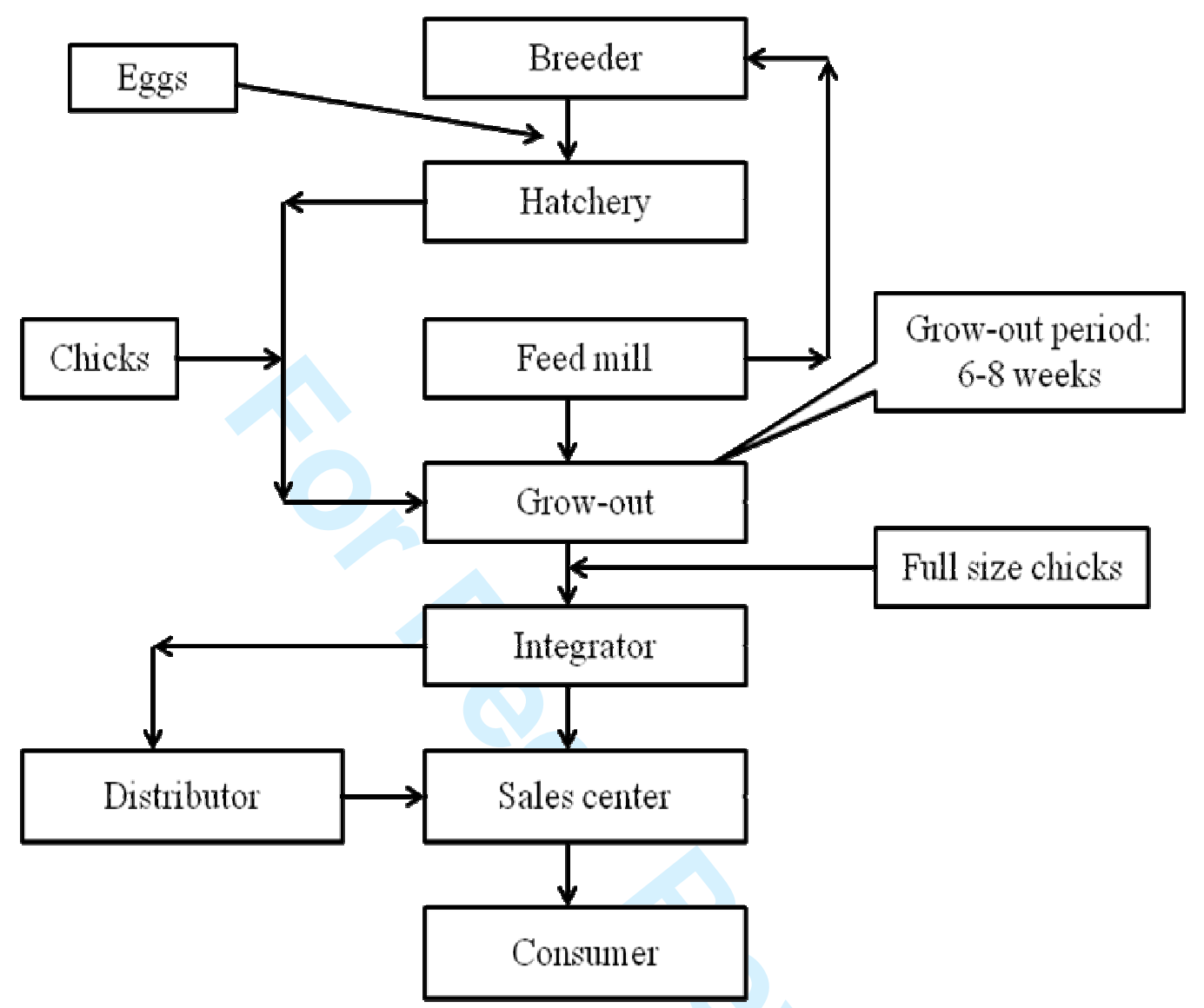

